The Quarterly Journal of Austrian Economics

Volume 22 | NO.4 | 603-619 | WiNTER 2019 WWW.QJAE.ORG

\title{
The Relevance of Bitcoin to the REgRESSION THEOREM: A REPLY TO LUTHER
}

\author{
George Pickering*
}

JEL Classification: B53, E42, E49

\begin{abstract}
АвsтRACт: Given Bitcoin's apparent lack of non-monetary uses, Luther (2018) argues that its emergence as a medium of exchange invalidates the regression theorem, or at least severely limits its relevance to identifying which commodities could emerge as media of exchange in the absence of State intervention. However, this view misinterprets both the regression theorem itself and the problem it was developed to address. The goal of the regression theorem was not to identify which commodities could become monies, but to provide a subjectivist explanation of the purchasing power of money. To do this, it requires only that some individuals valued the good in question before its use as a medium of exchange, not that it had some objective pre-monetary use.
\end{abstract}

\section{INTRODUCTION}

The emergence of Bitcoin and other private cryptocurrencies over 1 the past decade has posed a number of interesting questions for economists, and practitioners in the Austrian tradition have

\footnotetext{
*George Pickering (georgepickering@gmail.com) is a graduate student at the University of Oxford. The author would like to thank Dr. Luther and all the other participants at the Harwood Graduate Colloquium on Monetary Policy and Institutions, hosted at the American Institute for Economic Research from July 28-31, 2019, for their insightful discussion and comments on this topic.
} 
embraced the opportunity to judge these peculiar case studies against the established canon of Austrian monetary theories, and vice versa (Selgin 2014, Livera 2019). In particular, much attention has been paid to the relevance of cryptocurrencies to Ludwig von Mises's famous regression theorem (Davidson and Block 2013, Murphy 2014, Šurda 2014). One recent addition to this literature by Luther (2018) is representative of much of the broader conversation in that it judges the use of private cryptocurrencies as media of exchange to be a threatening counterexample to the validity of the regression theorem, while offering a novel and interesting justification for this familiar conclusion.

Luther argues that, due to Bitcoin's lack of obvious non-monetary uses, Austrian economists are left with two equally plausible conclusions to choose between: one can concede that Bitcoins actually are "intrinsically worthless," ${ }^{1}$ or one can reason that, since the regression theorem requires that media of exchange must have first had some non-monetary use, Bitcoin therefore must have had some pre-monetary use, even if that use was the mere satisfaction of the peculiar tastes of its early adopters. The first of these two conclusions, Luther argues, entirely invalidates the regression theorem, while the second preserves its validity by severely limiting its scope and prescriptiveness to the point of practical irrelevance. Specifically, Luther argues that the "practical relevance" of the regression theorem, which Bitcoin has swept away, was "in (1) distinguishing which items might emerge as money without government support and (2) offering suggestions as to how the government might launch a money that could not emerge naturally" (Luther 2018, 40).

Luther's argument is worth addressing not only for its own particular claims, but also because it rests on a misinterpretation of the regression theorem which is not uncommon in the broader conversation on cryptocurrencies. Mises's goal when formulating the regression theorem was not to explain the origin of money, nor to comment on which particular commodities could and could not spontaneously emerge as monies, nor even to advise governments

\footnotetext{
${ }^{1}$ Luther uses the unnecessarily confusing term "intrinsically worthless" to mean lacking in "value apart from any role the item might play as a medium of exchange" (Luther 2018, 33).
} 
on how to launch fiat monies, but specifically and exclusively to provide a subjectivist explanation of the present purchasing power of money. To do this, it requires only that the commodity in question was subjectively valued and exchanged by individuals prior to its use as a medium of exchange, not that it had some objective pre-monetary use.

\section{THE GOAL OF THE REGRESSION THEOREM}

Mises's goal when developing the regression theorem was to explain the purchasing power of money using Menger's subjective marginal utility theory of value. Previous authors (Helfferich [1903] $1923,577)$ had considered such an application of subjectivism impossible without falling into circular reasoning: money has purchasing power because individuals value it, but individuals only value money qua money because it has purchasing power. In order to break out of this circularity, Mises's regression theorem famously introduced the time dimension, arguing that individuals in fact value acquiring money in the present because they expect it will have purchasing power in the future, an expectation informed by the observable array of prices in the past.

Anticipating the criticism that this merely pushed the circularity problem backwards into an infinite regress problem, Mises emphasized that this regress did in fact have a concrete starting point at the time before the commodity ${ }^{2}$ in question was used as a medium of exchange, and was simply traded directly against other commodities on account of its own subjective valuation by consumers (Mises [1912] 1953, 120-21; Mises [1949] 1998, 405-08). "At this point the theory must hand over all further investigation to the general [subjective marginal utility] theory of value" (Mises [1912] 1953, 120).

Luther's assertion that the goals of the regression theorem extend beyond this explanation of money's purchasing power leaves us in the difficult position of attempting to prove a negative, especially given that his own interpretation of the purpose of the regression

\footnotetext{
${ }^{2}$ In this context, "commodity" should be taken broadly to mean something subjectively valued by individuals, rather than denoting a good with any particular physical characteristics.
} 
theorem is more an underlying assumption of his paper than one of its explicit, fully-stated arguments. However, in addition to our above summary of what the goals of the regression theorem were (and, by extension, were not) several other pieces of circumstantial evidence combine to undermine the persuasiveness of Luther's interpretation of the goals and "practical relevance" of the regression theorem.

Perhaps most fundamentally, the view that the regression theorem was an attempt to explain the origin of money and "which items might emerge as money without government support" (Luther 2018 , 40) sits ill at ease with the fact that Mises subscribed to Carl Menger's theory of the origin of money ([1871] 2007, 257-62; 1892), which he included uncritically in both The Theory of Money and Credit ([1912] 1953, 30-34) and Human Action ([1949] 1998, 398-404), going so far as to describe Menger's theory as "irrefutable" in the latter work (ibid., 402).

Furthermore, Mises's exposition of the regression theorem in The Theory of Money and Credit takes place in an entirely different section of the book from his discussion of the origin of money, separated by nearly 100 pages. In Human Action, Mises's discussion of the regression theorem takes place in a section explicitly marked as being concerned with "the determination of the purchasing power of money" (ibid., 405), rather than with its origins or the question of which particular commodities could become monies. After having completed his exposition of the regression theorem in The Theory of Money and Credit, Mises explicitly states that "the preceding investigation" had been "concerned to explain the origin of the objective exchange-value [i.e. the purchasing power] of money" ([1912] 1953, 123, emphasis added), rather than having been an attempted explanation of the origin of money, or what particular qualities a commodity must have to become money. Mises further stressed that the regression theorem does not claim that a money's present purchasing power is strictly determined or solely explained by the ratios at which consumers exchanged it prior to or apart from its role as a medium of exchange ([1949] 1998, 407), which handles any objection that the regression theorem is unable to account for Bitcoin's high purchasing power now relative to the humble rates at which it was originally exchanged against other goods. 
None of these facts could, in isolation, be said to prove the negative that the regression theorem has no relevance to the question of which particular types of commodities are capable of emerging spontaneously as monies. However, they all tend much more toward the view that the goal of the regression theorem was to provide a subjectivist explanation of the purchasing power of money, rather than to distinguish "which items might emerge as money without government support" (Luther 2018, 40).

\section{THE KEY REQUIREMENT OF THE REGRESSION THEOREM: SUBJECTIVE VALUE OR OBJECTIVE USE?}

In his article, Luther $(2018,39)$ explicitly distinguishes between a commodity's subjective valuation by individuals and its objective non-monetary uses, pointing to the latter as supposedly the more relevant to the question of whether Bitcoin violates the regression theorem:

\footnotetext{
There is no denying that some people valued bitcoin prior to its use as a medium of exchange. But the question is not whether people valued bitcoin; it is why people valued bitcoin. Did they value it because it had nonmonetary uses? [Emphasis original.]
}

If it were true that the regression theorem required that the money commodity must have had some objective use prior to its use as a medium of exchange, in order to have gained purchasing power, then it could conceivably be argued that Bitcoin still threatens the regression theorem regardless of that theorem's original goal. However, this is flatly not the case. Indeed, Mises repeatedly and explicitly emphasizes that "the original starting-point of the value of money was nothing but the result of subjective valuations" ([1912] 1953, 121, emphasis added). In this light, the idea that Bitcoin first gained purchasing power because individuals exchanged it directly due to their "peculiar preferences" (Luther 2018, 41), rather than due to any objective use, not only fails to threaten, but falls entirely in line with the regression theorem.

This subjectivist nature of the regression theorem is admittedly shrouded somewhat by Mises's unnecessarily confusing use 
of the word "industrial" to denote the qualities of the monetary commodity that might lead an individual to value it aside from its use as a medium of exchange.

However, a closer reading reveals that even this objective-sounding word masks a decidedly subjective definition: "to use it for industrial purposes, i.e., either for consumption [the direct satisfaction of one's subjective preferences] or for production" (Mises [1949] 1998, 406). This further emphasizes that it is subjective value, not objective uses, that the regression theorem requires a commodity to have originally possessed, in order to explain its purchasing power as a medium of exchange.

\section{CONCLUSION}

Luther (2018) misinterprets the purpose and requirements of the regression theorem in a manner that leads him to significantly overestimate "the constraint the regression theorem imposes on the set of potential monies" $(2018,42)$. The goal of the regression theorem was not to delimit which particular commodities can and cannot emerge as a money, but to explain the purchasing power of money using the subjective marginal utility theory of value. To do this, it requires only that the commodity in question was subjectively valued by individuals, and hence directly exchanged, prior to its use as a medium of exchange, not that it had some objective pre-monetary use. In light of this, it should be clear that the supposed threat posed to the regression theorem by the emergence of Bitcoin as a medium of exchange has been significantly overstated.

\section{REFERENCES}

Davidson, Laura, and Walter E. Block. 2013. "Bitcoin, the Regression Theorem, and the Emergence of a New Medium of Exchange." Quarterly Journal of Austrian Economics 18, no. 3: 311-38.

Helfferich, Karl. [1903] 1923. Das Geld. Leipzig: Hirschfeld.

Livera, Stephan. 2019. “Carl Menger on Currency Durability: A Lesson on Cryptos?" Mises Wire article, May 9. Accessed August 1, 2019. https:// mises.org/wire/carl-menger-currency- durability-lesson-cryptos. 
Luther, William J. 2018. "Is Bitcoin Intrinsically Worthless?" Journal of Private Enterprise 33, no. 1: 31-45.

Menger, Carl. [1871] 2007. Principles of Economics. Auburn, Ala.: Ludwig von Mises Institute.

—_. 1892. "On the Origin of Money." Economic Journal 2, no. 6: 239-55.

Mises, Ludwig von. [1912] 1953. The Theory of Money and Credit. New Haven: Yale University Press.

__ . [1949] 1998. Human Action. Auburn, Ala.: Ludwig von Mises Institute.

Murphy, Robert P. 2014. “On Bitcoin and Ludwig von Mises' Regression Theorem." Free Advice blog post, March 10. Accessed August 1, 2019. https://consultingbyrpm.com/blog/2014/03/on-bitcoin-and-ludwigvon-mises-regression-theorem.html.

Selgin, George. 2014. "Bitcoin: Problems and Prospects", prepared for Hillsdale University's 2014 Free Market Forum, Indianapolis, Ind., October 23- 25. Available at https:// www.hillsdale.edu/wp-content/ uploads/2016/02/FMF-2014-Bitcoin-Problems-and- Prospects.pdf.

Šurda,Peter.2014. “TheOrigin,ClassificationandUtility ofBitcoin." Available at https://papers.ssrn.com/sol3/papers.cfm?abstract_id=2436823. 